\title{
Malignant Synovial Neoplasm
}

National Cancer Institute

\section{Source}

National Cancer Institute. Malignant Synovial Neoplasm. NCI Thesaurus. Code C6531.

A malignant neoplasm that affects the synovium. 